\title{
A Brief Study of Fish Market Systems and Development of a Fish Market Based Mobile Application
}

\author{
Lijina $\mathbf{P}^{1}$, Nandakumar $\mathbf{P}^{2}$ \\ PG Scholar, ECE Department, NSS College of Engineering, Palakkad, Kerala, India ${ }^{1}$ \\ Professor, ECE Department, NSS College of Engineering, Palakkad, Kerala, India ${ }^{2}$
}

\begin{abstract}
The rapid development of technology enables to perform tasks without human intervention in this era of digital businesses and business moments. This work plans to describe the process of development of an Android application for a fish market which is a smartphone application that helps to know about the fish market details, to conduct an e-auction of fish and to perform the whole calculations regarding the market. The existing system of market works similarly in most of the countries in a conventional way. The existing system can't provide any method for preplanning, to know about the market details and also there is a repeated number of phone calls between the stakeholders. By developing an android application, the total system can be made easy and transparent. The proposed system will account for a smarter fish marketing process.
\end{abstract}

Keywords: Android, Smartphone application, Fish marketing system, e-auction

\section{INTRODUCTION}

\section{A. Brief study about existing system of fish market}

National Fisheries Development Board conducted study on domestic fish marketing in India [7]. Under the Constitution of India fishery is considered as a state subject. But only a few states are practicing specific policies for fish marketing. In India the domestic fish marketing system is neither modern nor efficient. It is mainly carried out by private traders with a number of intermediaries like auctioneer, wholesaler, retailer and vendor between producer and consumer and they perform various functions while marketing fish. In freshwater fish marketing, the auctioneers employ or source fish through a commission agent while retailers sell fish directly to consumers. Also in some cases several groups of retailers participate in auction process for buying the fish. Vendors are found selling the fish directly at the consumer's doorstep. The study described about the need for creating a uniform policy for fish marketing for easier operation and regulation. Then only country's total fish production can be efficiently managed and delivered. The improvement in fish marketing system would definitely contribute to the food and nutritional security of a majority of our population who are associated with fish market system and fish trade.

[8] This study review the fish trading system and tries to provide a well framework for the development of a fish auction system. As price changes from time to time depending on the fish availability and on the market situation, the transaction method followed is usually direct negotiation between buyers and sellers. The two types of fish auction systems prevailing are the incremental and the detrimental system. The former or the Dutch system is widely followed in Europe while the latter or the American system is practiced in many Asian countries. Usually auctions are conducted early in the morning and gets completed within a few hours. Auction systems can create a transparency in fish trading. The widespread use of technology, especially the use of mobile phones can make the system more transparent as all the stakeholders can have access to information regarding market and latest market prices updates.

[9] In case of manual auctions, errors in communicating prices during the transactions compromised between the guarantee of security and transparency

Considering the use of electronic auctions in fish trading sector[10], the advantage of both with considerable experience and newcomers are alike. The evolution of technology and internet has neutralized the advantages for whole classes. While few existing electronic auctions take the advantage of remote bidding opportunities.

This study [11] analyses the macro-environmental factors surrounding the new fish wholesale market in Oman. It determines the market stakeholders, their impacts on the market operation and the basic needs and management 


\section{International Advanced Research Journal in Science, Engineering and Technology}

Vol. 6, Issue 4, April 2019

procedures for efficient market operations. In order to achieve the objectives of this study information was collected based on literature review of reports and related studies about wholesale markets and fish marketing systems. Electronic auction provides transparency and fairness to all participants - buyers and sellers - within an auditable process. The electronic sales offer the possibility of trade employing a variety of options for bidding patterns. The auctions may operate a closed network, a distributed open network or even on a remote server over the internet and buyers may still bid by voice with the auctioneer recording their offer or do so whilst hundreds of kilometers from the place of sale using the internet. Electronic auction has many advantages for different stakeholder groups, but at the same time the advantage for one player may be seen by another as a disadvantage. The adoption of electronic system in fish market provides openness, fairness and transparency where the market is not restricted to a single physical location. It enables the concentration of supply and buyers and promotes better quality and traceability. In addition some of the barriers can eliminate system efficiency including the ability to adopt a stringent quality and traceability control along the distribution channel.

\section{B. Purpose of this research}

The purpose of the development of this application is to ease traders, commission agents and mini traders about knowing the market details and to create a convenient and easy-to-use application for smarter fish marketing. It will have a database showing details of fish market from three different viewpoints, a provision for conducting an e-auction for fish and a way to handle accounts and payment to provide a comfortable user experience.

\section{Benefits of this research}

The benefit of this research is that any member of our society with a smartphone usage knowledge who is associated with a fish market can experience a smarter fish marketing by using this android application.

\section{Research problem}

Based on the above description, the formulation of the problem is;

1. How can a smartphone application be developed and used for the development of a leading industry and trade sector like fish market?

\section{E. Literature review on app development}

Nowadays Smart phones have become an irresistible part of everyone's life. With these smart phones the human life is changed for better. The software can be made for mobile phones, this is called app. There are different operating systems for different mobile phones but the $83 \%$ of mobile users uses android based mobile phones.

In [12], for development of android applications, there are certain guidelines and rules to be followed which are listed in the "Mobile application development -a practical approach". The app developers least significantly adapt the existing software development processes to suit their purpose. This leads to variations in existing processes and introduces new trends hence establishing new guidelines for the developers. So there is need of official documentation of guidelines for app development, which we have also followed in the app development process. These listings are very helpful as an instructional manual for developing the app.

This paper focuses on development a framework. These three components are interdependent on each other by the flow of the system [2]. Developing a frameworks is very important things because the frameworks plays an important role as a guideline in guiding the entire process of the research study.

[3] It describes about the reasons to say "why having an e-commerce app is beneficial to business" And how advantageable it is to have an e-commerce mobile app for business because it helps to target the audience globally and increases online visibility of the business. It helps in building brand recognition and makes it easy for the customers to reach. It allows to communicate with customers and interact with them. It keeps the customers engaged with the products.

[1] Mobile phones today have moved beyond their fundamental role of communications and have graduated to become an extension of the persona of the user. The capabilities of mobile networks are increasing rapidly, extending the scope of applications. Mobile application (m-app) refers to a software program that has been developed for small low-power handheld devices such as mobile phones or tablets. These applications are either pre-installed on devices during manufacture, or downloaded by customers from app stores and other mobile software.

[5] Android is a mobile operating system running on the Linux Kernel. It was initially developed by Android Inc., a firm later purchased by Google, and lately by the Open Handset Alliance. It allows developers to write managed code in the Java language, controlling the device via Google-developed Java Libraries. The unveiling of the Android 


\title{
International Advanced Research Journal in Science, Engineering and Technology
}

\author{
Vol. 6, Issue 4, April 2019
}

distribution on 5 November 2007 was announced with the founding of the Open Handset Alliance, a consortium of 47 hardware, software and telecom companies devoted to advancing open standards for mobile devices. Google released most of the Android code under the Apache License, a free software and open source license.

The proper utilization of mobile's in today era can yield a better result for mankind. In this research, the main target was on the development of the fisheries sector with the help of Android mobile application.

\section{METHODS}

\section{A. Stages of research}

1) Phase 1: Literature study

In this stage, a study about fish marketing system in different areas have been done along with the study of development of a mobile application using android studio platform.

2) Phase 2: Design of the smartphone application

In this stage, knowledge about how to design and develop a prototype mobile application in accordance with the specified platform is carried out.

3) Phase 3: Development of a section of the smartphone application

A particular portion of the android application to conduct the e-auction platform has been created in this stage. In the next stage, the complete application with all the supporting features for different class of stakeholders will be created.

4) Phase 4: Documentation, Reporting, and International Journal Submission

This stage involves preparing the documentation as a report and writing-up the results of the research for publication in an international scientific journal

\section{B. Location of research}

The research have been conducted in the PG laboratory of the respective institution. The data collection methodology included primary and secondary data collection methods from different stakeholders of different markets located nearby.

\section{RESULTS AND DISCUSSIONS}

\section{A. Results}

The portion of smartphone application created was using android studio software for android platform. While the next stage development may include other supporting softwares. The created portion was to conduct an e-auction for fish for fish markets. It will benefit the class of market traders and mini traders among the discussed set of stakeholders.

\section{TARGET PEOPLE}

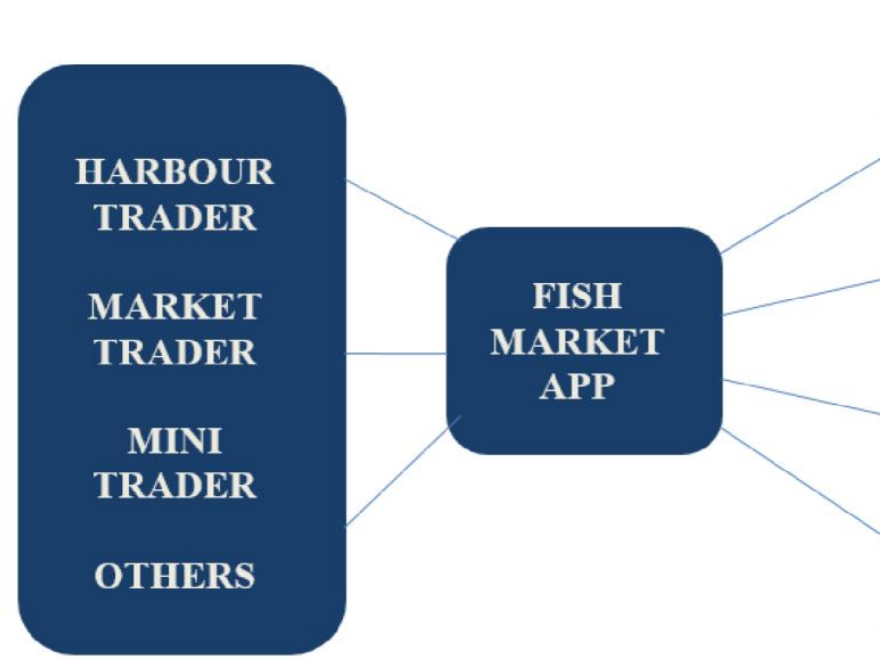

Fig 1: Simple outline of the app

\section{SERVICES OFFERED}

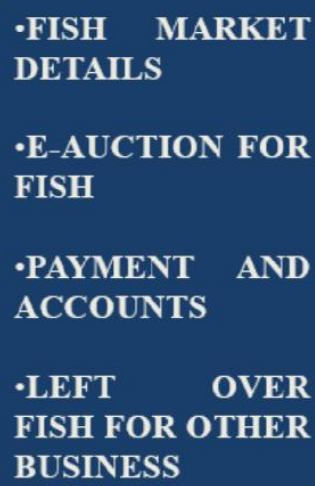




\section{International Advanced Research Journal in Science, Engineering and Technology}

Vol. 6, Issue 4, April 2019
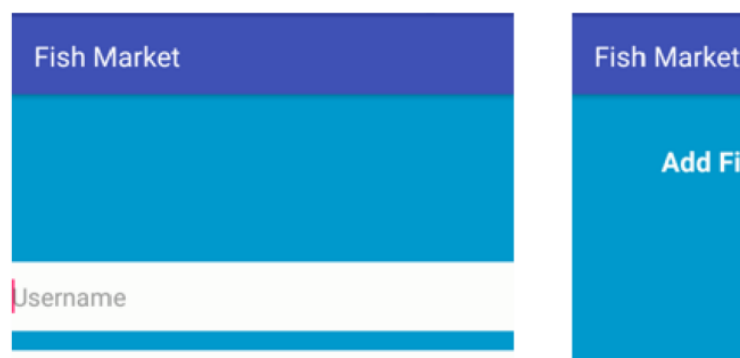

Password
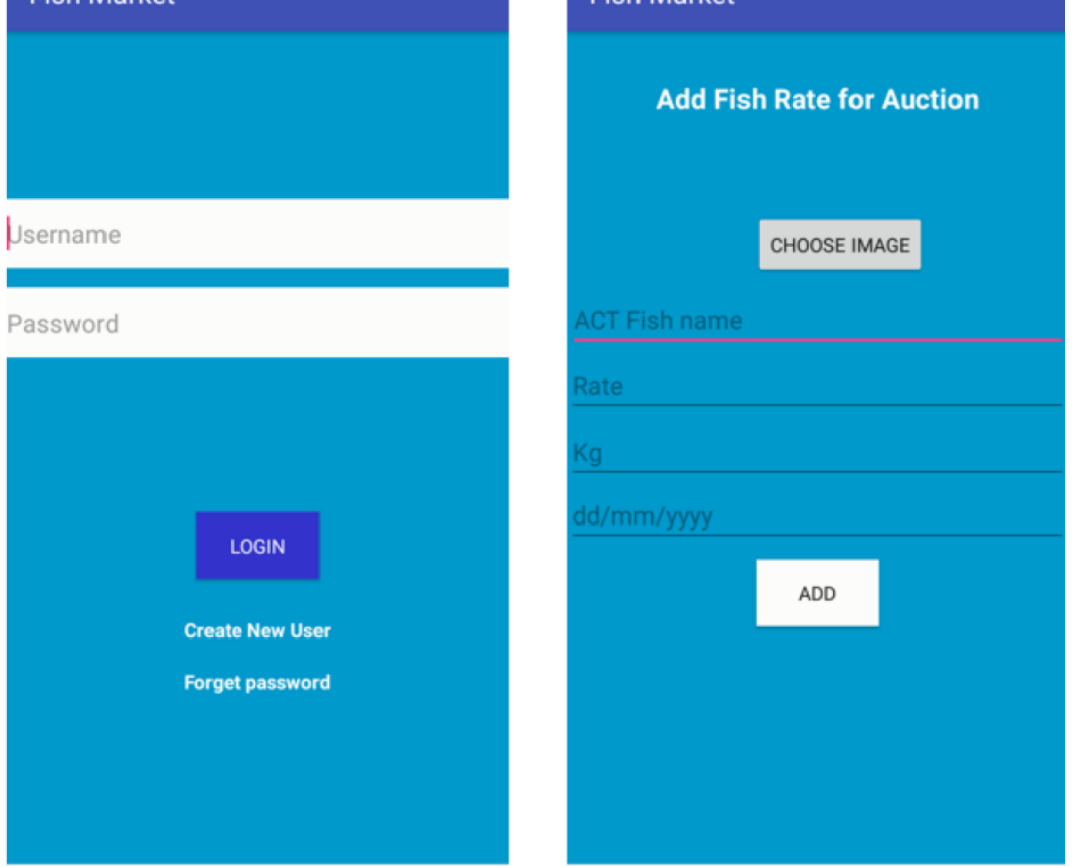

Fig 1: Login Page and e-auction page
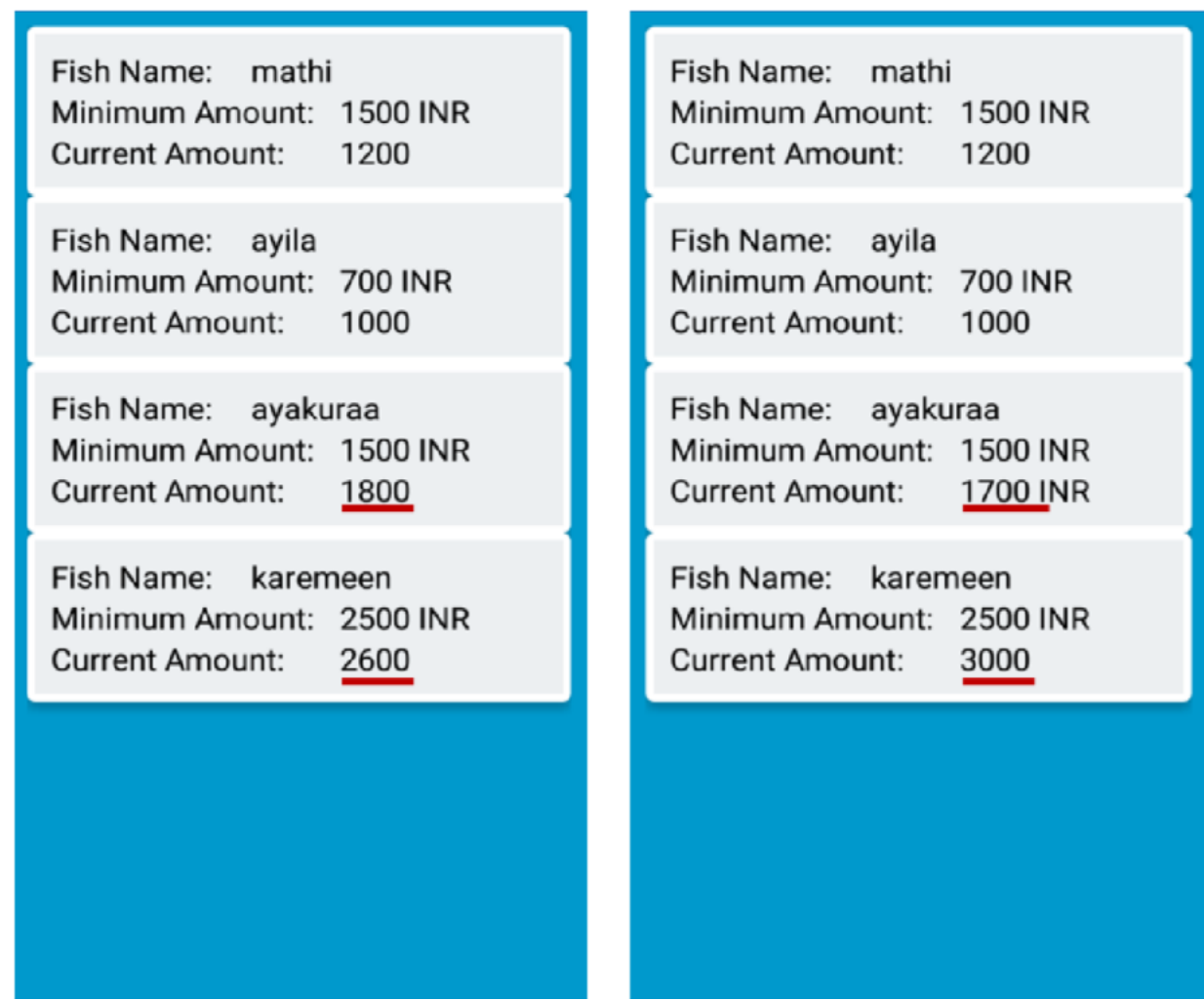

Fig 2: E-auction data pages

\section{B. Discussions}

It shows that development of this application would be a great benefit for the set of stakeholders like harbor traders, market traders, mini traders and others who need the left over fish. Also it would help in building a more improved fish marketing system in our country as our country is one among the leading producers of fish in the world. On developing the next stage the application may get completed and will be beneficial for the specific group of population who are our study group. 


\title{
International Advanced Research Journal in Science, Engineering and Technology
}

\author{
Vol. 6, Issue 4, April 2019
}

\section{CONCLUSIONS}

The following tentative conclusions can be reached after this first stage:

A. The investigation for seeking the knowledge of fish marketing systems in various areas were studied and analyzed. Also the required knowledge was gathered to build a simple android application.

B. The complete framework for the design of the application was created based on requirements of each stakeholder group as different modules for them. Also it helped in analyzing their needs better.

C. Result activities have so far focused on gathering the required background knowledge and developing a framework because once the framework is ready, it is easy to develop the application as per the needs.

\section{REFERENCES}

[1]. Jha Ashish K, Bababe Adam B, Dr. Ashok K. Sahoo, Plant Disease Information Generating System Based On Android Application Technology, International Journal of Science and Research (IJSR) · April 2017

[2]. Mohd Afizi Mohd Shukran, Muhammad Naim Abdullah, Mohd Rizal Mohd Isa , Mohd Nazri Ismail, Mohammad Adib Khairuddin, Kamaruzaman Maskat, Developing A Framework for Accident Detecting and Sending Alert Message Using Android Application, International Journal of Engineering \& Technology, 2018.

[3]. How to develop an e-commerce mobile app

[4]. Akshay Khedaskar, Suyog Gaikwad, Ruchir Tawade, Megha Naik, College Managemnt System Based On Android Application Using Cloud Computing. International Journal of Computer Engineering and Applications, Volume XI, May 17.

[5]. Kodrat Iman Satoto, Eko Didik Widianto, Sumardi, Environmental Health Monitoring with Smartphone Application, $5^{\text {th }}$ International Conference On Information Technology, Computer and Electrical Engineering, 2018

[6]. Ms. Niharika Dedhia, Dr. V. C. Kotak, Android Based Campus Solution For College Management System, International Journal of Computer Science and Mobile Computing, Vol.6 Issue.11, November- 2017.

[7]. B. Ganesh Kumar, K.K. Datta, P.K. Joshi, P.K. Katiha, R. Suresh, T. Ravisankar, K. Ravindranath and Muktha Menon, Domestic Fish Marketing in India - Changing Structure, Conduct, Performance and Policies, Agricultural Economics Research Review · January 2008

[8]. Sudari Pawiro, Study On The Establishment Of A Fish Auction System In Hue-Viet Nam, Regional Fisheries Livelihoods Programme for the and Southeast Asia Viet Nam Component, May 2011

[9]. Electronic auctions for the Fish Market in Pescara-Enhancing auction operations \& services by using an innovative Axis network video system

[10]. Crick Carleton, Electronic fish auctions-Strategies for securing and maintaining comparative advantage in the seafood trade, March 2000

[11]. Salim Qatan, Operating a wholesale fish market in the sultanate of oman - Analyses of external factors, Ministry of Fisheries Wealth, 2010

[12]. Lizeth Ghandi, Catarina Silva, Tatiana Gualotuna, Mobile application development process - a practical experience, Information Systems and Technologies (CISTI), 2017 12th Iberian Conference 